\title{
A produção das pausas no processo de entoação realizada por professores na leitura de textos narrativos
}

DOI: http://dx.doi.org/10.21165/el.v49i3.2565

\section{Rosicleide Rodrigues Garcia'}

\section{Resumo}

A análise automatizada utilizando o programa ExProsódia (FERREIRA NETTO, 2010) por meio da leitura do miniconto "Não conseguiu dormir. Mas ao amanhecer lembrou-se de todos os seus sonhos" (SILVA, 2017), realizada por 40 professores do ensino fundamental ao médio, verificou que não existe uma regularidade de leitura quanto ao uso de pausas e produções de frases entoacionais. Tendo em vista os conceitos de pausas definidas por Nespor e Vogel (1986), pode-se observar que 90\% dos professores realizaram pausas, porém, a forma como elas foram produzidas não estabelece um parâmetro entre eles. Quanto à execução de frases entoacionais, também não houve simetria de resultados, sabendo-se que 23 deles produziram apenas uma frase entoacional, 11 fizeram duas e seis realizaram até três. Sendo assim, nota-se que não há uma estandardização entre os professores, possibilitando-nos discussões acerca do trabalho do professor em sala de aula, assim como o ensino de língua portuguesa.

Palavras-chave: fonologia; entoação; leitura; professores ensino básico.

1 Universidade de São Paulo (USP), São Paulo, São Paulo, Brasil; prof.rosicleide@outlook.com, http://orcid.org/0000-0001-9857-961X 


\title{
The production of pauses in the intonation process performed by teachers in reading narrative texts
}

\begin{abstract}
The automated analysis using the ExProsódia program (FERREIRA NETTO, 2010) has verified that there is no regular reading as to the use of pauses and production of intonation phrases by reading the flash fiction "He couldn't sleep. But he remembered all his dreams at dawn" (SILVA, 2017), carried out by 40 elementary and middle schoolteachers. Given the concepts of pauses defined by Nespor and Vogel (1986), the research has observed that $90 \%$ of the teachers took breaks; however, the way they were produced does not establish a parameter between them. Regarding the execution of intonation sentences, there was no symmetry of results either, because 23 of them produced only one intonation sentence, 11 made two, and six made three. Thus, it is possible to understand that there is no standardization among teachers, enabling us discussions about the teacher's work in the classroom, as well as the teaching of the Portuguese language.
\end{abstract}

Keywords: phonology; intonation; lecture; elementary school teachers.

\section{Introdução}

Esta pesquisa pertence às análises de pós-doutoramento Não importa somente ler, mas como se ler: estudo sobre o processo de mudança da entoação e sua importância para a compreensão de textos verbais, cujo objetivo é verificar a entoação utilizada por professores e alunos do ensino básico, de modo a perceber se existe uma padronização de leitura de acordo com aquilo que é previsto pela literatura científica. Tal qual visto por Cagliari (2002, p. 57), ao informar que:

As pessoas aprendem a ler na escola 'dominando as emoções', lendo o mais 'neutramente' possível, usando um ritmo constante, usando a variação melódica apenas para casos indispensáveis, enfim, como ensinam os professores, fazendo uma leitura fluente, e isso significa, foneticamente, que o aluno precisa ler grupos tonais não muito curtos, de preferência do tamanho das frases, deve usar o tom 3 em sequências até chegar a um tom 1, se a frase for declarativa. [...] 0 foco dos enunciados deve ser sempre no final da frase, local ideal para a tônica saliente que, por sua vez deve ser marcada apenas pela entoação e não por outros elementos prosódicos. [...] O leitor e o ouvinte recriam o que leem, em grande parte, pela maneira como atribuem os elementos prosódicos ao texto escrito ou lido à moda da escola. 
Logo, sabendo que a entoação tende a ser regulada, este artigo busca ampliar essa discussão e apresentar a observação realizada de como os professores produzem as pausas durante o processo de leitura.

Essa preocupação é tida, já que é fato notório a pausa ser uma das constituintes da prosódia, assim como a intensidade e a duração vocálica. E, ao lembrarmo-nos de Fónagy (2003, p. 2) ao explicitar que "a articulação prosódica da mensagem é a condição fundamental da interpretação", vamos ao encontro da justificativa desta pesquisa que nasce de um questionamento de um aluno do ensino médio que, após acompanhar a leitura de um poema de Camões realizado por sua professora, perguntou-lhe o motivo de ele não conseguir interpretá-lo quando fazia a leitura para si mesmo, mas a compreendia muito bem quando realizada pela profissional.

Tomando essa dúvida como um problema fono-pedagógico, a primeira hipótese é que muitos alunos não reconheçam a prosódia de um texto, fazendo com que a entoação não seja aplicada de forma plena de maneira a favorecer a própria compreensão. Ademais, sabendo-se da importância das pausas no ato da comunicação oral ou escrita, tevese como proposta primeiramente observar a sua realização na fala de 40 (quarenta) professores de diversas disciplinas do ensino básico - fundamental e médio, de modo a entender como ela vem sendo produzida em aulas, não apenas de Língua Portuguesa.

Para esta análise, como base teórica foram utilizados os estudos de Cagliari (2002) sobre leitura e prosódia, Nespor e Vogel (1986) sobre a classificação das pausas, e Marcuschi (2003) sobre a utilização destas; assim como os trabalhos desenvolvidos por Ferreira Netto e equipe (2008 a atual), já que se trata de uma pesquisa desenvolvida dentro do Projeto ExProsódia.

\section{A sintaxe e a prosódia}

Para se realizar a análise da leitura, foi escolhido o miniconto da escritora Neide Silva (2017): "Não conseguiu dormir. Mas ao amanhecer lembrou-se de todos os seus sonhos", que se deu por seu teor literário escapar de uma articulação prevista pela gramática normativa. Isto é, o texto é constituído por três períodos oracionais distribuídos em duas frases, sendo a primeira um período simples e a segunda, composto.

A primeira, declarativa, poderia se estabelecer como uma coordenada assindética, de modo que fosse seguida pela coordenada sindética adversativa. Todavia, a autora preferiu encerrá-la com ponto e iniciar a segunda frase contrapondo-a com a afirmação anterior. Além disso, intercalou-se uma subordinada adverbial temporal que não fora isolada por vírgulas. Dessa forma, a primeira frase torna-se categórica, enquanto a segunda traz o teor poético. 
De modo geral, a compreensão sintática dá apoio à análise do discurso e, consecutivamente, os elementos prosódicos devem estar ligados a essa estrutura. Segundo Cagliari (2002, p. 42-43),

A sintaxe encontra na frase sua especificidade maior, mas se não levar em conta o discurso em que se encaixa, corre o risco de interpretar mal, até mesmo coisas básicas do nível da frase, com sujeito e predicado, tópico e comentário, relações dêiticas e anafóricas, etc. [...]

Os elementos prosódicos servem para ponderar os valores semânticos dos enunciados, sendo uma das formas de que dispõe o falante para dizer a seu interlocutor como ele deve proceder diante do que ouve.

Sendo assim, embora o autor nos informe que os leitores, de modo geral, fazem um texto conforme sua intuição (CAGLIARI, 2002), e de que haja a orientação de que as pessoas tenham de ler "dominando as emoções" (p. 57), ele demonstra como essas percepções quanto ao uso da prosódia são falhas, pois, em seu estudo, Cagliari discute que a prosódia e a análise do discurso estariam por caminhos perdidos, pois não caminham em conjunto com a estrutura do discurso.

Logo, por meio dessas considerações, percebemos que as pausas estabelecidas nos textos escritos por meio da pontuação e a função sintática dos elementos possuem uma lógica que pode não ser seguida na leitura, na reinterpretação oral do texto. E o miniconto escolhido, devido à sua complexidade, revelaria essa tendência: hipoteticamente, a percepção sintática levaria a considerar a existência de duas a três pausas perceptíveis durante a sua leitura. Ou seja, a primeira após o ponto, a segunda depois da conjunção e a terceira ao final da oração subordinada adverbial; ou a segunda pausa aparecer após a subordinada. Porém, o leitor também poderia cumprir apenas uma pausa perceptível ao final da primeira sentença, desconsiderando as demais por estas não terem sido marcadas por vírgulas na construção do texto.

\section{As pausas e a prosódia}

Como dito, o principal elemento prosódico considerado para a constituição da pesquisa foi a pausa, pois, de acordo com Marcuschi (2003, p. 63), "as pausas podem ser curtas (micropausas), médias ou longas e constituem um fator decisivo na organização do texto conversacional".

Embora estejamos analisando o texto lido e não a conversação, traz-se aqui a visão de Dahlet (2006, p. 294), em que se considera a escrita como a imagem incorporada da voz, da transcrição da fala, levando-se em conta a entoação, cadência, pausas e ritmo. Nesse 
contexto, os textos escritos buscam, por meio de sua pontuação, ressaltar os elementos da fala, de modo que o leitor iria "ouvir" a entoação das vozes representadas (id, p. 300).

Dessa forma, é natural que, ao reproduzir a leitura, mesmo que haja a moderação prevista por Cagliari (2002), o leitor busque equiparar essa voz interna à do autor, trazendo pausas quando há pontos ou vírgulas, ou mesmo trazendo breves interrupções quando se intercalam períodos ou termos.

Para isso, considerar-se-á os estudos de Nespor e Vogel (1986), que definem as pausas como (1) perceptual - que se refere ao que é percebido como pausa, podendo foneticamente corresponder a uma variedade de fenômenos, como mudança de pitch e de duração, e que só algumas vezes corresponde à cessão da fonação - e (2) real relativa à existência de porção de silêncio no sinal da fala.

Sendo assim, para definir como perceptuais as pausas mais longas como fronteiras de unidades, adotar-se-á o modelo de Ferreira Netto e Martins (2019, p. 6), que as reconhece a partir de uma duração mínima de 300 ms. Em tempo, os autores adotaram essa medida baseada na literatura científica que considera as interrupções perceptíveis com variações entre $200 \mathrm{~ms}$ a $450 \mathrm{~ms}$. Tais dados foram gerados e registrados pelo programa ExProsódia, que mediu não tão somente as pausas, mas a entoação realizada pelos informantes.

\section{Sobre a metodologia}

Conforme informado, foram selecionados 40 professores do ensino básico de diversas disciplinas, sendo especificamente 10 (dez) do fundamental I, 30 (trinta) do fundamental Il e ensino médio. Desses dois últimos, não foi realizada uma divisão, pois é muito comum que a partir do $6^{\circ}$ ano os professores atuem em ambas as categorias.

A proposta de se fazer um levantamento com professores de diversas cátedras deve-se ao fato de os alunos estarem expostos às várias execuções de leitura durante o período em que estão em ambiente escolar, não sendo apenas responsabilidade dos professores de língua portuguesa a implementação desse aprendizado.

Dessa forma, após a coleta, as gravações foram editadas pelo programa Audacity 1.3.12 Beta (Unicode), e, consecutivamente, verificadas e convertidas em curvas de frequência fundamental e de curva de intensidade para arquivos de texto pelo software Speech Filing System (HUCKVALE, 2008). Por fim, os dados obtidos foram analisados pelo aplicativo ExProsódia (FERREIRA NETTO, 2010), em que se observaram as pausas, o número de frases entoacionais produzido pelos informantes, as médias do tom médio (TM) e tom final (TF), assim como suas direções - se proeminentemente descendentes ou ascendentes - e a finalização, se plagal ou autêntica. 


\section{0 uso do ExProsódia para a análise de dados}

O ExProsódia é um sistema de análise automática da entoação na língua portuguesa, e tem por objetivo "propor uma interpretação para a relação entre a entoação e a fala" (FERREIRA NETTO, 2016, p. 6). Para isso, o programa considera a entoação como uma sucessão de sons, iguais ou diferentes, que ocorrem durante a fala. Sob esse viés, constitui-se uma série temporal, pois o conjunto dos componentes criados pela frequência, intensidade e duração dos tons são sequenciadas e dependentes entre si (id, p. 8).

Em suma, o ExProsódia assume a hipótese de Xu e Wang (1997) e decompõe o ritmo tonal em finalização (F), sustentação (S) e foco/ênfase (E). Assim, a fala é convertida de semitons (st) a uma base decimal linear, e obtêm-se valores válidos de $\mathrm{f}_{0}$, o qual revela o tom médio (TM) do falante, e a quão articulada é a sua pronúncia a partir da análise da finalização: se plagal - menos marcada entoacionalmente - ou autêntica - em que a pronúncia é mais acentuada (FERREIRA NETTO, 2010).

De acordo com Ferreira Netto (2016, p. 11-12),

[...] a componente $F$ (finalização) é o tom alvo da declinação pontual, estabelecida por um intervalo ideal decrescente de 7 st do TM obtido até o momento Z(t). O TM é a tendência central dos valores válidos de $F_{0}$ calculada como a média aritmética acumulada no tempo que são categorizadas por um intervalo sistêmico lateral de 3 st acima e 4 st abaixo do valor médio de cada uma (MARTINS; FERREIRA NETTO, 2010; 2011).

Ademais, para este estudo também foram observadas as convoluções das UBI (sigla adaptada de Unit of base of intonation), que se tratam das unidades básicas da análise automática. Consoante Ferreira Netto e Martins (2019, p. 9),

O princípio linguístico adotado para sua definição é de que a variação de $F_{0}$ não se dá exclusivamente dentro dos limites da uma unidade fonológica, como o segmento ou a sílaba e pode ter dimensões variadas. Deste modo, uma sequência como [da.dv] teria somente uma UBI, definida pela sonoridade dos elementos que a compõem. Por sua vez, a palavra [da.te] teria, em tese, duas UBIS: da/-a.

Estas, segundo o autor (2016, p. 18), "consideram tanto a quantidade de ocorrências de pausas, em relação à quantidade de UBIs - Pausa/UBI -, quanto suas durações intrínsecas, em ms". 
Gráfico 1. Na figura abaixo, temos a decomposição dos elementos foco/ênfase (F/E), finalização (F) e sustentação (S)

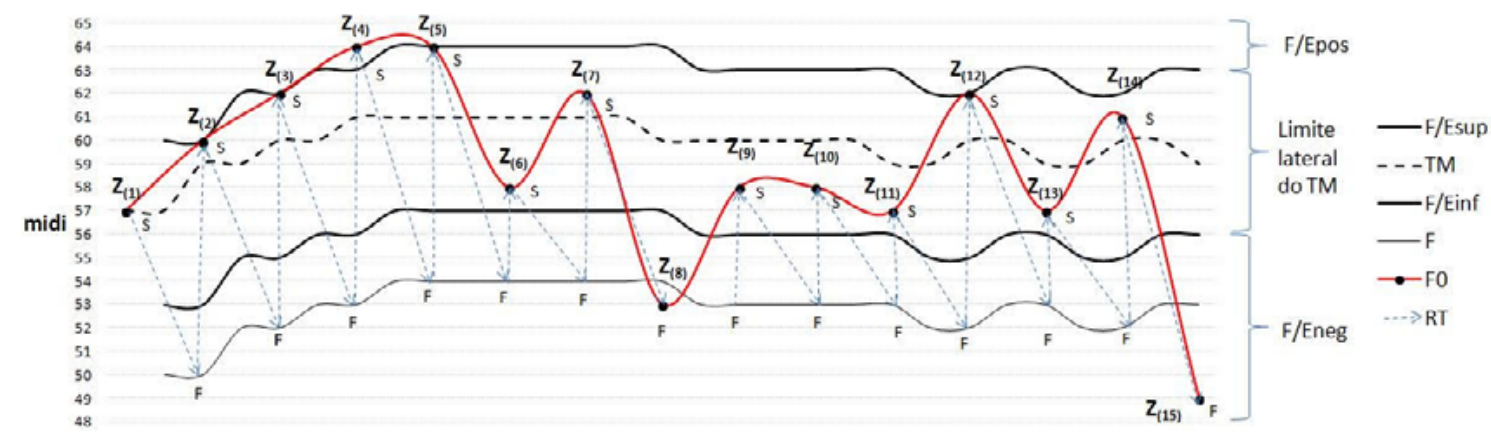

Fonte: Ferreira Netto (2016, p. 11)

Por meio do gráfico 1, retirado da última compilação de estudos realizados pelo sistema ExProsódia, podemos compreender o funcionamento do sistema por meio da representação do Ritmo Tonal, marcado com linhas azuis pontilhadas, numa ocorrência efetiva de $F_{0^{\prime}}$ marcado pela linha vermelha contínua. Os valores à esquerda estão em escala midi. As siglas $Z$ indicam cada um dos momentos mensurados de $F_{0}$ (UBIs); as siglas F, as finalizações supostas, sendo a que vai marcada no momento $Z$ (8) e a última à direita (Z(15)) as que realmente se realizaram; as siglas $S$ indicam os pontos de sustentação supostos, que estabelecem o Tom Médio.

Gráfico 2. Na figura abaixo, tem-se a representação da pausa
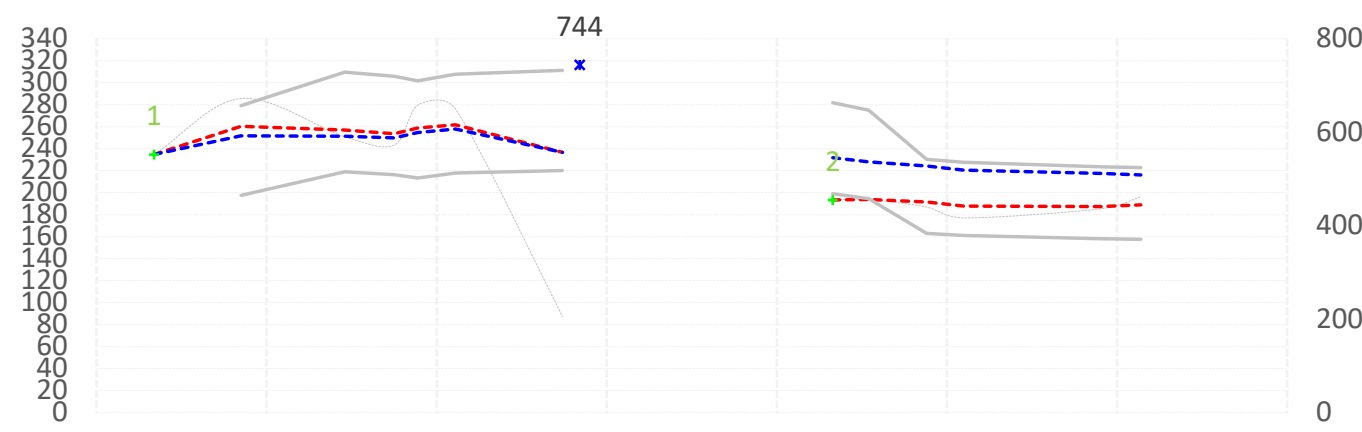

Fonte: Elaboração própria

Para observarmos as pausas, o sistema também cria gráficos como esse, em que é possível notar uma descontinuidade entre os vetores. Nele, temos o eixo vertical à esquerda revelando os valores em Hertz; à direita, em milissegundos (ms). A linha contínua acima é relativa ao TM superior (F/E sup), e a linha contínua abaixo é o TM inferior ( $F / E$ inf). A linha cinza pontilhada é o $F_{0}$ das UBIs; a vermelha pontilhada é o TM/ reset; e a azul pontilhada é o TM/total, referente à variação global. 0 asterisco marca o início da pausa em 744 ms. 
Nesta representação, reconhece-se que o informante realizou duas frases entoacionais, a primeira marcada pelo número 1 e a segunda, após a pausa, pelo número 2. Sendo assim, é possível notar a pausa silenciosa, marcada por 744 ms.

\section{Análise do processo entoacional}

A primeira análise traz os resultados obtidos representados nas tabelas a seguir.

Tabela 1. Valores obtidos a partir da análise da leitura de professores do ensino básico, níveis Fundamental II e Médio

\begin{tabular}{|c|c|c|c|c|c|c|c|c|}
\hline Professor & $\begin{array}{c}\text { Frase } \\
\text { Entoacional }\end{array}$ & $\begin{array}{l}\text { Média } \\
\text { de } F_{0}\end{array}$ & $\begin{array}{l}\text { UBI } \\
\text { final }\end{array}$ & Direção & Movimento & Alvo & \multicolumn{2}{|c|}{ Pausa } \\
\hline BIO 1 & $\begin{array}{l}1 \\
2 \\
\end{array}$ & $\begin{array}{l}151,58 \\
162,49 \\
\end{array}$ & \begin{tabular}{|l|}
116,08 \\
140,69 \\
\end{tabular} & $\begin{array}{c}\text { Descendente } \\
\text { Ascendente }\end{array}$ & $\begin{array}{l}\text { Oblíqua } \\
\text { Oblíqua }\end{array}$ & $\begin{array}{c}\text { Autêntica } \\
\text { Plagal }\end{array}$ & 1 & $405 \mathrm{~ms}$ \\
\hline $\mathrm{BIO} 2$ & 1 & 110,63 & 104,72 & Descendente & Oblíqua & Plagal & 1 & $909 \mathrm{~ms}$ \\
\hline $\mathrm{BIO} 3$ & $\begin{array}{l}1 \\
2 \\
3 \\
\end{array}$ & $\begin{array}{c}257,97 \\
95,68 \\
207,03 \\
\end{array}$ & $\begin{array}{c}260,40 \\
95,68 \\
197,21 \\
\end{array}$ & $\begin{array}{l}\text { Ascendente } \\
\text { Descendente } \\
\text { Descendente }\end{array}$ & $\begin{array}{l}\text { Oblíqua } \\
\text { Pontual } \\
\text { Oblíqua }\end{array}$ & $\begin{array}{l}\text { Plagal } \\
\text { Plagal } \\
\text { Plagal } \\
\end{array}$ & 1 & $1109 \mathrm{~ms}$ \\
\hline EF 1 & 1 & 124,83 & 103,82 & Descendente & Oblíqua & Plagal & 1 & $504 \mathrm{~ms}$ \\
\hline EF 2 & $\begin{array}{l}1 \\
2 \\
3 \\
\end{array}$ & $\begin{array}{l}201,68 \\
148,22 \\
168,87 \\
\end{array}$ & $\begin{array}{c}110,13 \\
81,13 \\
178,90 \\
\end{array}$ & $\begin{array}{l}\text { Descendente } \\
\text { Descendente } \\
\text { Ascendente }\end{array}$ & $\begin{array}{l}\text { Pontual } \\
\text { Pontual } \\
\text { Oblíqua } \\
\end{array}$ & $\begin{array}{c}\text { Autêntica } \\
\text { Autêntica } \\
\text { Plagal }\end{array}$ & $\begin{array}{l}2 \\
0 \\
0\end{array}$ & $\begin{array}{l}400 \mathrm{~ms} \\
470 \mathrm{~ms}\end{array}$ \\
\hline FIS 1 & $\begin{array}{l}1 \\
2 \\
\end{array}$ & $\begin{array}{l}236,79 \\
188,84 \\
\end{array}$ & $\begin{array}{c}87,27 \\
196,42 \\
\end{array}$ & $\begin{array}{c}\text { Descendente } \\
\text { Ascendente }\end{array}$ & $\begin{array}{l}\text { Pontual } \\
\text { Oblíqua }\end{array}$ & $\begin{array}{c}\text { Autêntica } \\
\text { Plagal }\end{array}$ & 1 & $744 \mathrm{~ms}$ \\
\hline FIS 2 & 1 & 124,35 & 111,18 & Ascendente & Oblíqua & Plagal & 1 & $654 \mathrm{~ms}$ \\
\hline GEO 1 & 1 & 211,47 & 163,35 & Ascendente & Oblíqua & Autêntica & 1 & $350 \mathrm{~ms}$ \\
\hline GEO 2 & 1 & 152,74 & 112,72 & Descendente & Oblíqua & Autêntica & 1 & $674 \mathrm{~ms}$ \\
\hline HIST 1 & 1 & 213,53 & 196,40 & Descendente & Oblíqua & Plagal & 1 & $749 \mathrm{~ms}$ \\
\hline HIST 2 & 1 & 185,34 & 114,85 & Descendente & Oblíqua & Autêntica & 1 & $859 \mathrm{~ms}$ \\
\hline INFO 1 & $\begin{array}{l}1 \\
2 \\
3 \\
\end{array}$ & $\begin{array}{l}403,68 \\
328,51 \\
350,84 \\
\end{array}$ & $\begin{array}{l}425,10 \\
317,52 \\
323,73 \\
\end{array}$ & $\begin{array}{l}\text { Descendente } \\
\text { Descendente } \\
\text { Descendente }\end{array}$ & $\begin{array}{l}\text { Oblíqua } \\
\text { Oblíqua } \\
\text { Oblíqua }\end{array}$ & $\begin{array}{l}\text { Plagal } \\
\text { Plagal } \\
\text { Plagal } \\
\end{array}$ & 1 & $799 \mathrm{~ms}$ \\
\hline INFO 2 & $\begin{array}{l}1 \\
2 \\
\end{array}$ & $\begin{array}{l}189,04 \\
160,62 \\
\end{array}$ & $\begin{array}{l}141,91 \\
152,92 \\
\end{array}$ & $\begin{array}{l}\text { Descendente } \\
\text { Descendente }\end{array}$ & $\begin{array}{l}\text { Pontual } \\
\text { Oblíqua }\end{array}$ & $\begin{array}{c}\text { Autêntica } \\
\text { Plagal }\end{array}$ & 1 & $1099 \mathrm{~ms}$ \\
\hline ING 1 & $\begin{array}{l}1 \\
2 \\
\end{array}$ & $\begin{array}{l}300,82 \\
227,38 \\
\end{array}$ & \begin{tabular}{|l|}
281,44 \\
258,26 \\
\end{tabular} & $\begin{array}{c}\text { Descendente } \\
\text { Ascendente }\end{array}$ & $\begin{array}{l}\text { Oblíqua } \\
\text { Oblíqua }\end{array}$ & $\begin{array}{l}\text { Plagal } \\
\text { Plagal } \\
\end{array}$ & 1 & $509 \mathrm{~ms}$ \\
\hline ING 2 & 1 & 198,00 & 202,50 & Ascendente & Pontual & Plagal & 0 & \\
\hline MAT 1 & 1 & 228,24 & 174,00 & Descendente & Oblíqua & Autêntica & 0 & \\
\hline
\end{tabular}




\begin{tabular}{|c|c|c|c|c|c|c|c|c|}
\hline MAT 2 & $\begin{array}{l}1 \\
2 \\
3 \\
\end{array}$ & $\begin{array}{r}192,44 \\
159,08 \\
166,99 \\
\end{array}$ & $\begin{array}{l}162,11 \\
159,08 \\
137,85 \\
\end{array}$ & $\begin{array}{l}\text { Descendente } \\
\text { Descendente } \\
\text { Descendente }\end{array}$ & $\begin{array}{l}\text { Pontual } \\
\text { Oblíqua } \\
\text { Pontual }\end{array}$ & $\begin{array}{c}\text { Autêntica } \\
\text { Plagal } \\
\text { Autêntica }\end{array}$ & 1 & $1084 \mathrm{~ms}$ \\
\hline MAT 3 & $\begin{array}{l}1 \\
2\end{array}$ & $\begin{array}{l}231,97 \\
184,99\end{array}$ & $\begin{array}{l}145,44 \\
170,63\end{array}$ & $\begin{array}{l}\text { Descendente } \\
\text { Descendente }\end{array}$ & $\begin{array}{l}\text { Pontual } \\
\text { Oblíqua }\end{array}$ & $\begin{array}{c}\text { Autêntica } \\
\text { Plagal }\end{array}$ & $\begin{array}{l}0 \\
2\end{array}$ & $\begin{array}{l}430 \mathrm{~ms} \\
270 \mathrm{~ms}\end{array}$ \\
\hline MAT 4 & 1 & 176,42 & 144,00 & Descendente & Oblíqua & Autêntica & 1 & $644 \mathrm{~ms}$ \\
\hline MAT 5 & $\begin{array}{l}1 \\
2 \\
3 \\
\end{array}$ & $\begin{array}{l}266,63 \\
254,27 \\
227,95 \\
\end{array}$ & $\begin{array}{l}229,64 \\
171,67 \\
220,96 \\
\end{array}$ & $\begin{array}{l}\text { Descendente } \\
\text { Descendente } \\
\text { Descendente }\end{array}$ & $\begin{array}{l}\text { Pontual } \\
\text { Pontual } \\
\text { Oblíqua } \\
\end{array}$ & $\begin{array}{c}\text { Plagal } \\
\text { Autêntica } \\
\text { Plagal } \\
\end{array}$ & 1 & $639 \mathrm{~ms}$ \\
\hline MAT 6 & 1 & 229,90 & 195,60 & Descendente & Oblíqua & Autêntica & 0 & \\
\hline QUIM 1 & $\begin{array}{l}1 \\
2 \\
3 \\
\end{array}$ & $\begin{array}{l}193,72 \\
183,72 \\
174,03 \\
\end{array}$ & $\begin{array}{l}103,00 \\
159,10 \\
171,18 \\
\end{array}$ & $\begin{array}{l}\text { Descendente } \\
\text { Descendente } \\
\text { Descendente }\end{array}$ & $\begin{array}{l}\text { Pontual } \\
\text { Pontual } \\
\text { Oblíqua } \\
\end{array}$ & $\begin{array}{c}\text { Autêntica } \\
\text { Autêntica } \\
\text { Plagal }\end{array}$ & 1 & $1099 \mathrm{~ms}$ \\
\hline QUIM 2 & 1 & 159,05 & 128,85 & Descendente & Oblíqua & Autêntica & 2 & $\begin{array}{l}305 \mathrm{~ms} \\
855 \mathrm{~ms}\end{array}$ \\
\hline
\end{tabular}

Fonte: Elaboração própria

Tabela 2. Valores obtidos a partir da análise da leitura de professores de Língua Portuguesa do ensino básico, níveis Fundamental II e Médio, e das polivantes, nível Fundamental I

\begin{tabular}{|c|c|c|c|c|c|c|c|c|}
\hline Professor & $\begin{array}{c}\text { Frase } \\
\text { Entoacional }\end{array}$ & $\begin{array}{l}\text { Média } \\
\text { de F0 }\end{array}$ & $\begin{array}{l}\text { UBI } \\
\text { final }\end{array}$ & Direção & Movimento & Alvo & \multicolumn{2}{|c|}{ Pausa } \\
\hline POLI 1 & $\begin{array}{l}1 \\
2 \\
\end{array}$ & $\begin{array}{l}206,10 \\
168,04 \\
\end{array}$ & $\begin{array}{r}88,13 \\
184,71 \\
\end{array}$ & $\begin{array}{l}\text { Descendente } \\
\text { Ascendente }\end{array}$ & $\begin{array}{l}\text { Pontual } \\
\text { Oblíqua }\end{array}$ & $\begin{array}{c}\text { Autêntica } \\
\text { Plagal }\end{array}$ & 2 & $\begin{array}{l}355 \mathrm{~ms} \\
210 \mathrm{~ms}\end{array}$ \\
\hline POLI 2 & 1 & 201,20 & 211,23 & Ascendente & Oblíqua & Plagal & 1 & $450 \mathrm{~ms}$ \\
\hline POLI 3 & 1 & 182,55 & 168,00 & Descendente & Oblíqua & Plagal & 2 & $\begin{array}{l}345 \mathrm{~ms} \\
435 \mathrm{~ms}\end{array}$ \\
\hline POLI 4 & $\begin{array}{l}1 \\
2 \\
\end{array}$ & $\begin{array}{l}300,05 \\
224,16 \\
\end{array}$ & $\begin{array}{l}288,67 \\
217,24 \\
\end{array}$ & $\begin{array}{l}\text { Descendente } \\
\text { Descendente }\end{array}$ & $\begin{array}{l}\text { Oblíqua } \\
\text { Oblíqua }\end{array}$ & $\begin{array}{l}\text { Plagal } \\
\text { Plagal } \\
\end{array}$ & $\begin{array}{l}1 \\
2 \\
\end{array}$ & $\begin{array}{l}799 \mathrm{~ms} \\
624 \mathrm{~ms} \\
\end{array}$ \\
\hline POLI 5 & 1 & 265,06 & 183,93 & Descendente & Oblíqua & Autêntica & 1 & $\begin{array}{l}549 \mathrm{~ms} \\
519 \mathrm{~ms} \\
\end{array}$ \\
\hline POLI 6 & $\begin{array}{l}1 \\
2 \\
\end{array}$ & $\begin{array}{l}278,48 \\
203,29 \\
\end{array}$ & $\begin{array}{l}281,17 \\
183,89 \\
\end{array}$ & $\begin{array}{l}\text { Ascendente } \\
\text { Descendente }\end{array}$ & $\begin{array}{l}\text { Oblíqua } \\
\text { Oblíqua }\end{array}$ & $\begin{array}{l}\text { Plagal } \\
\text { Plagal } \\
\end{array}$ & 1 & $684 \mathrm{~ms}$ \\
\hline POLI 7 & 1 & 179,37 & 167,64 & Descendente & Oblíqua & Plagal & 1 & $709 \mathrm{~ms}$ \\
\hline POLI 8 & 1 & 266,16 & 231,76 & Descendente & Oblíqua & Autêntica & 1 & $809 \mathrm{~ms}$ \\
\hline POLI 9 & $\begin{array}{l}1 \\
2 \\
\end{array}$ & $\begin{array}{l}252,30 \\
211,33 \\
\end{array}$ & $\begin{array}{l}177,44 \\
199,54 \\
\end{array}$ & $\begin{array}{l}\text { Descendente } \\
\text { Ascendente }\end{array}$ & $\begin{array}{l}\text { Pontual } \\
\text { Oblíqua }\end{array}$ & $\begin{array}{c}\text { Autêntica } \\
\text { Plagal }\end{array}$ & 1 & $465 \mathrm{~ms}$ \\
\hline POLI 10 & 1 & 247,59 & 195,37 & Descendente & Oblíqua & Autêntica & 1 & $\begin{array}{l}639 \mathrm{~ms} \\
599 \mathrm{~ms}\end{array}$ \\
\hline
\end{tabular}




\begin{tabular}{c|c|c|c|c|c|c|c|c}
\hline PORT 1 & 1 & 205,06 & 198,90 & Ascendente & Oblíqua & Plagal & 0 & \\
\hline PORT 2 & 1 & 203,38 & 198,49 & Descendente & Pontual & Plagal & 1 & $599 \mathrm{~ms}$ \\
\hline PORT 3 & 1 & 202,91 & 173,11 & Ascendente & Oblíqua & Autêntica & 1 & $584 \mathrm{~ms}$ \\
\hline PORT 4 & 1 & 176,63 & 171,33 & Descendente & Oblíqua & Plagal & 1 & $589 \mathrm{~ms}$ \\
\hline PORT 5 & 1 & 205,38 & 194,69 & Ascendente & Oblíqua & Autêntica & 0 & \\
\hline PORT 6 & 1 & 201,76 & 121,70 & Descendente & Pontual & Autêntica & 1 & $829 \mathrm{~ms}$ \\
& 2 & 170,78 & 155,56 & Descendente & Oblíqua & Plagal & & \\
\hline \multirow{2}{*}{ PORT 7 } & 1 & 173,62 & 117,50 & $\begin{array}{c}\text { Descendente } \\
\text { Pontual }\end{array}$ & $\begin{array}{c}\text { Putêntica } \\
\text { Plagal }\end{array}$ & 2 & $\begin{array}{l}769 \mathrm{~ms} \\
450 \mathrm{~ms}\end{array}$ \\
\hline
\end{tabular}

Fonte: Elaboração própria

Primeiramente, na primeira coluna, foram descritas as disciplinas às quais pertencem os professores do ensino básico dos níveis fundamental II e Médio. Observa-se nela a contribuição de professores da área de Biologia/Ciências (BIO), Educação Física (EF), Física (FIS), Geografia (GEO), História (HIST), Informática (INFO), Inglês (ING), Matemática (MAT), Química (QUIM), Polivalentes (POLI) e Língua Portuguesa (PORT). Na segunda coluna, há o número de frases entoacionais realizadas por cada profissional; enquanto na terceira, vemos a média obtida de $F_{0}$ seguida da média de UBI final: ambos os dados foram medidos em Hertz e o cálculo gerado pelo programa ExProsódia.

As mesmas descrições são válidas para a tabela 2, que foi colocada separadamente como fator pedagógico para demonstrar que mesmo os professores polivalentes (POLI), pertencentes ao nível Fundamental I, quanto os de Língua Portuguesa (PORT), dispostos entre o Fundamental II e Médio - aqueles comumente responsáveis por ensinar a leitura aos alunos -, possuem características semelhantes aos da tabela 1 em algumas análises, e outras que se diferem, principalmente quando se trata de direção entoacional e alvo.

A direção, ascendente ou descendente, refere-se à curva de $F_{0^{\prime}}$ assim como seu movimento, se pontual ou oblíquo. No caso, direção descendente revela uma proposição grave enquanto a ascendente é aguda.

Os alvos autêntico e plagal são relativos à finalização realizada no processo entoacional, conforme explicado anteriormente. Por fim, a coluna que expressa "pausa" informa se houve o processo de interrupção durante a leitura e quantos ocorreram, demarcando a medida em milissegundos.

Em análise, dos 40 professores divididos em ambas as tabelas, sendo 23 para a primeira e 17 para a segunda, em relação à composição das frases entoacionais, verificamos 
que $57 \%$ do total de informantes realizaram 1 frase entoacional e $43 \%$ formaram de 2 a 3 contornos entoacionais para a leitura do mesmo miniconto. Ainda que observemos os dados separadamente, vemos que não são tão distintos, sendo que, para a tabela 1 , temos $51 \%$ de informantes produzindo 1 frase entoacional contra $65 \%$ dos profissionais da tabela 2. Por fim, é notável que os professores polivalentes e de língua portuguesa não produziram nenhuma leitura com 3 frases entoacionais.

Tabela 3. Número de frases entoacionais produzidas pelos professores

\begin{tabular}{c|c|c|c}
\hline \multicolumn{5}{c}{ FRASES ENTOACIONAIS } \\
\hline & 1 frase & 2 frases & 3 frases \\
\hline Tabela 1 & 12 & 5 & 6 \\
\hline Tabela 2 & 11 & 6 & 0 \\
\hline TOTAL & 23 & 11 & 6 \\
\hline
\end{tabular}

Fonte: Elaboração própria

O mesmo ocorre para a análise da direção entoacional, se descendente ou ascendente: nota-se que o número de direções descendentes é maior em ambas as tabelas, totalizando a diferença de $67 \%$ em relação à ascendente.

Analisando mais atentamente, os professores da tabela 1 produzem uma direção mais acentuada, chegando a $74 \%$ contra $59 \%$ da tabela 2 . Em tempo, chamou-se "misto" o caso em que o informante realizou duas frases entoacionais e cada uma delas apresentou uma direção.

Tabela 4. Número de realizações de frases com direção entoacional descendente, ascendente e mista realizadas pelos professores

\begin{tabular}{c|c|c|c}
\hline \multicolumn{4}{|c}{ DIREÇÃO ENTOACIONAL } \\
\hline & Descendente & Ascendente & Misto \\
\hline Tabela 1 & 17 & 3 & 3 \\
\hline Tabela 2 & 10 & 4 & 3 \\
\hline TOTAL & 27 & 7 & 6 \\
\hline
\end{tabular}

Fonte: Elaboração própria

Quanto ao movimento, se oblíquo ou pontual, o mesmo valor de $67 \%$ repete-se, porém, para o movimento oblíquo. Isso significa que a frase entoacional obteve acento frasal durante a sua execução. Logo, em linhas gerais, apresentaram-se $71 \%$ da execução do movimento oblíquo contra $65 \%$ da tabela 1. 
Novamente, foi utilizada a nomenclatura "misto" para indicar os casos em que o informante realizou duas frases entoacionais e apresentou ambos os movimentos nelas.

Tabela 5. Número de realizações de frases com movimento entoacional oblíquo, pontual e misto realizado pelos professores

\begin{tabular}{c|c|c|c}
\hline \multicolumn{5}{c}{ MOVIMENTO ENTOACIONAL } \\
\hline & Oblíquo & Pontual & Misto \\
\hline Tabela 1 & 15 & 5 & 3 \\
\hline Tabela 2 & 12 & 1 & 4 \\
\hline TOTAL & 27 & 6 & 7 \\
\hline
\end{tabular}

Fonte: Elaboração própria

Por fim, os alvos, que são as finalizações das frases entoacionais, obtiveram resultados muito semelhantes. No total, foram $43 \%$ de finalizações plagais, contra $37 \%$ de autênticas e $20 \%$ de mistas, em que os informantes apresentaram ambas as finalizações em suas frases entoacionais.

Porém, quando as tabelas são vistas separadamente, nota-se que a realização plagal se acentua com os professores da tabela 2 , sendo $47 \%$ de alvos plagais, contra $29 \%$ de autêntico e $24 \%$ mistos. Em contrapartida, os informantes da tabela 2 realizaram $44 \%$ de alvos autênticos, contra 39\% de plagais e 17\% misto.

Tabela 6. Número de realizações de frases com finalizações autêntica, plagal e mista realizadas pelos professores

\begin{tabular}{c|c|c|c}
\hline \multicolumn{5}{c}{ ALVO / FINALIZAÇÃo } \\
\hline & Autêntica & Plagal & Misto \\
\hline Tabela 1 & 10 & 9 & 4 \\
\hline Tabela 2 & 5 & 8 & 4 \\
\hline TOTAL & 15 & 17 & 8 \\
\hline
\end{tabular}

Fonte: Elaboração própria

\section{Sobre a realização de pausas}

Após analisar-se o processo entoacional, compreende-se como são dadas as pausas: como visto nas tabelas 1 e 2, a realização de uma ou mais frases entoacionais não determina se o informante realizará pausas reais. Percebe-se tal afırmação ao observamos o caso de POLI5, em que o profissional proferiu uma frase entoacional e produziu duas 
pausas perceptuais com cerca de 500 ms de duração. Assim como houve o caso de PORT1 que, mesmo produzindo 18 UBIs, não realizou pausas perceptíveis.

Conforme explicado anteriormente, as UBIs representam a unidade básica de entoação, ou seja, uma medida fonológica formada por uma sílaba ou um segmento. Logo, o conjunto dessas UBIs consegue definir as ocorrências das frases entoacionais, a articulação utilizada ao ser dita determinada informação e a identificação de pausas perceptíveis, tendo em vista a breve interrupção entre o término de uma unidade e o início de outra. Destarte, levando em consideração o miniconto estudado, o professor que proferiu as 17 UBIs demonstra uma pronúncia extremamente articulada, diferentemente de quem emitiu apenas 5 UBIs, por ter trazido uma segmentação mais indissociável dos elementos fonológicos, não marcando fronteiras perceptíveis ao ouvinte.

Em se tratando da identificação das pausas, nota-se que 90\% dos professores as realizaram, porém, não se estabelece um parâmetro entre eles. Essa ausência de padronização é realizada de tal maneira que, conforme visto na tabela 7 , nem os profissionais das disciplinas teoricamente responsáveis pela introdução de uma leitura mais estandardizada (POLI e PORT) possuem um regramento absoluto na fala em relação à quantidade de UBIs antes de realizarem uma pausa real.

Para compreendermos tais afirmações, é importante iniciarmos a análise da quantidade de UBIs registradas, pois constatou-se que 64\% dos informantes produziram de 12 a 15 UBIs e $13 \%$ realizaram de 16 a $18 \mathrm{UBI}$. Isso significa que, na maioria dos casos, houve mais acuidade ao se articular as frações sonoras, o que nos leva a compreender que as unidades fonológicas tiveram fronteiras bem estabelecidas, mas não de formas iguais.

Embora a maioria tenha realizado uma boa articulação, 19\% de professores promoveram 10 e 11 UBIs, o que significa uma pronúncia menos enfática. Ademais, constataram-se $4 \%$ que constituíram sua frase entoacional com 5 e 8 UBIs, conforme visto no gráfico 3. 
Gráfico 3. Quantidade de UBIs realizadas pelos professores. A linha x mostra a quantidade de informantes e a linha y mostra a quantidade de UBIs proferidas

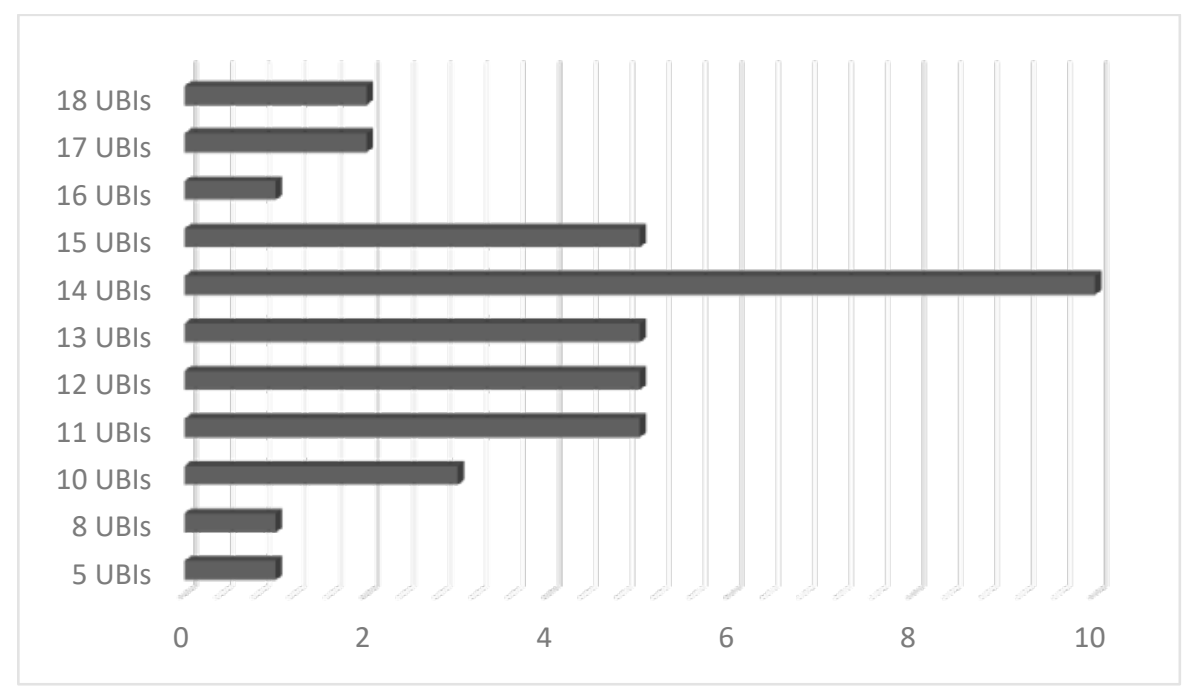

Fonte: Elaboração própria.

Além das diferenças de pronúncia que as UBIs demonstram, ao analisá-las, percebese que as pausas não são realizadas nas mesmas posições, conforme mencionado anteriormente. Para entendermos melhor, observemos a tabela 7 em que estão divididos: (i) na primeira coluna, a descrição dos informantes por disciplina correspondente; (ii) na segunda coluna, o número total de UBIs executado por eles; (iii) na terceira e quinta coluna, a quantidade de unidades básicas de entoação que foram produzidas até haver as pausas (identificada como "após UBIs"); e (iv) nas colunas 4 e 6, o registro em milissegundos de cada interrupção, caso tenha ocorrido.

Assim, ao analisar os dados, percebemos o caso de $\mathrm{BIO1}$ que realizou $14 \mathrm{UBIs}$ em duas frases entoacionais, sendo que, no primeiro sintagma, após 4 UBIs ele realizou uma pausa de $405 \mathrm{~ms}$. Tal realização ocorreu durante a leitura do primeiro período do miniconto, em "Não conseguiu dormir", respeitando-se o ponto ao final da sentença e com a pausa perceptual coincidente à finalização da primeira frase entoacional. Todavia, observando outra situação de ING2 que também realizou 14 UBIs, percebe-se que não houve estabelecimento de pausa perceptível. Por fim, os dados de QUIM2 trazem a mesma quantidade de UBIs aqui exemplificada, mas após 3 UBIs, a professora produziu uma pausa perceptual de 305 ms, e, depois de mais 9 UBIs, realizou outra pausa de 855 ms em uma única frase entoacional. 
Tabela 7. Total de UBIs e pausas realizadas em frases entoacionais pelos professores.

\begin{tabular}{|c|c|c|c|c|c|}
\hline & $\begin{array}{l}\text { UBIs } \\
\text { total }\end{array}$ & $\begin{array}{l}\text { UBIs realizadas } \\
\text { antes da } 1^{\text {a }} \text { pausa }\end{array}$ & $1^{\text {a }}$ pausa & $\begin{array}{l}\text { UBIs realizadas } \\
\text { antes da } 2^{\mathrm{a}} \text { pausa }\end{array}$ & $2^{\mathrm{a}}$ pausa \\
\hline $\mathrm{BIO1}$ & 14 & 4 & $405 \mathrm{~ms}$ & & \\
\hline $\mathrm{BlO} 2$ & 10 & 6 & $910 \mathrm{~ms}$ & & \\
\hline $\mathrm{BIO}$ & 14 & 7 & $1110 \mathrm{~ms}$ & & \\
\hline EF 1 & 11 & 4 & $415 \mathrm{~ms}$ & 5 & $505 \mathrm{~ms}$ \\
\hline EF 2 & 17 & 2 & $400 \mathrm{~ms}$ & - & $470 \mathrm{~ms}$ \\
\hline FIS 1 & 13 & 7 & $745 \mathrm{~ms}$ & & \\
\hline FIS 2 & 5 & 5 & $655 \mathrm{~ms}$ & & \\
\hline GE01 & 14 & 10 & $350 \mathrm{~ms}$ & & \\
\hline GEO2 & 13 & 8 & $675 \mathrm{~ms}$ & & \\
\hline HIST1 & 11 & 7 & $750 \mathrm{~ms}$ & & \\
\hline HIST2 & 10 & 8 & $860 \mathrm{~ms}$ & & \\
\hline INFO1 & 11 & 7 & $800 \mathrm{~ms}$ & 1 & $385 \mathrm{~ms}$ \\
\hline INFO2 & 14 & 9 & $1100 \mathrm{~ms}$ & & \\
\hline ING1 & 12 & 7 & $510 \mathrm{~ms}$ & & \\
\hline ING2 & 14 & - & - & & \\
\hline MAT1 & 14 & 10 & $470 \mathrm{~ms}$ & & \\
\hline MAT2 & 11 & 7 & $1084 \mathrm{~ms}$ & & \\
\hline MAT3 & 14 & 8 & $430 \mathrm{~ms}$ & 1 & $270 \mathrm{~ms}$ \\
\hline MAT4 & 13 & 8 & $645 \mathrm{~ms}$ & & \\
\hline MAT5 & 12 & 9 & $640 \mathrm{~ms}$ & & \\
\hline MAT6 & 14 & - & - & & \\
\hline QUIM1 & 10 & 8 & $1100 \mathrm{~ms}$ & & \\
\hline QUIM2 & 14 & 3 & $305 \mathrm{~ms}$ & 9 & $855 \mathrm{~ms}$ \\
\hline POLI1 & 12 & 3 & $355 \mathrm{~ms}$ & 3 & $210 \mathrm{~ms}$ \\
\hline POLI2 & 15 & 9 & $450 \mathrm{~ms}$ & & \\
\hline POLI3 & 13 & 8 & $345 \mathrm{~ms}$ & - & $435 \mathrm{~ms}$ \\
\hline POLI4 & 8 & 5 & $800 \mathrm{~ms}$ & - & $625 \mathrm{~ms}$ \\
\hline POLI5 & 15 & 8 & $550 \mathrm{~ms}$ & 2 & $520 \mathrm{~ms}$ \\
\hline POLI6 & 15 & 8 & $685 \mathrm{~ms}$ & & \\
\hline POLI7 & 16 & 7 & $710 \mathrm{~ms}$ & & \\
\hline
\end{tabular}




\begin{tabular}{c|c|c|c|c|c}
\hline POLI8 & 14 & 8 & $810 \mathrm{~ms}$ & & \\
\hline POLI9 & 17 & 9 & $465 \mathrm{~ms}$ & & \\
\hline POLI10 & 13 & 3 & $235 \mathrm{~ms}$ & 9 & $640 \mathrm{~ms}$ \\
\hline PORT1 & 18 & - & - & & \\
\hline PORT2 & 12 & 7 & $600 \mathrm{~ms}$ & & \\
\hline PORT3 & 11 & 7 & $585 \mathrm{~ms}$ & & \\
\hline PORT4 & 18 & 9 & $590 \mathrm{~ms}$ & 4 & $300 \mathrm{~ms}$ \\
\hline PORT5 & 15 & - & - & & \\
\hline PORT6 & 15 & 8 & $830 \mathrm{~ms}$ & & \\
\hline PORT7 & 12 & 7 & $770 \mathrm{~ms}$ & 1 & $450 \mathrm{~ms}$ \\
\hline
\end{tabular}

Fonte: Elaboração própria

Para ilustrar esses dados em imagem, temos o exemplo de MAT2, visto no gráfico 4, em que a pausa de 1084 ms acontece após 7 UBIs, e há a ocorrência de 3 frases entoacionais. A primeira coincide com o período "não conseguiu dormir" e a informante produz uma média de duração da UBIfınal medida em 162,10 ms, o que explica produção notável de UBIs no primeiro período e lhe possibilita uma maior articulação na produção das unidades. A segunda frase entoacional, compreendida em "mas ao amanhecer", e a terceira, "lembrou-se de todos os seus sonhos", embora com entoações distintas, são geradas com um pouco menos de articulação, não reproduzem pausas, e registram a média de 137,84 ms em suas unidades. A saber, no gráfico 4 temos o eixo vertical à esquerda revelando os valores em Hertz; à direita, em milissegundos (ms). A linha contínua acima é relativa ao TM superior (F/E sup), e a linha contínua abaixo é o TM inferior ( $F / E$ inf). A linha cinza pontilhada é o $F_{0}$ das UBIs; a vermelha pontilhada é o TM/ reset; e a azul pontilhada é o TM/total, referente à variação global. Por fım, o asterisco marca o início da pausa em 1084 ms.

Gráfico 4. Na figura abaixo, tem-se a representação da pausa

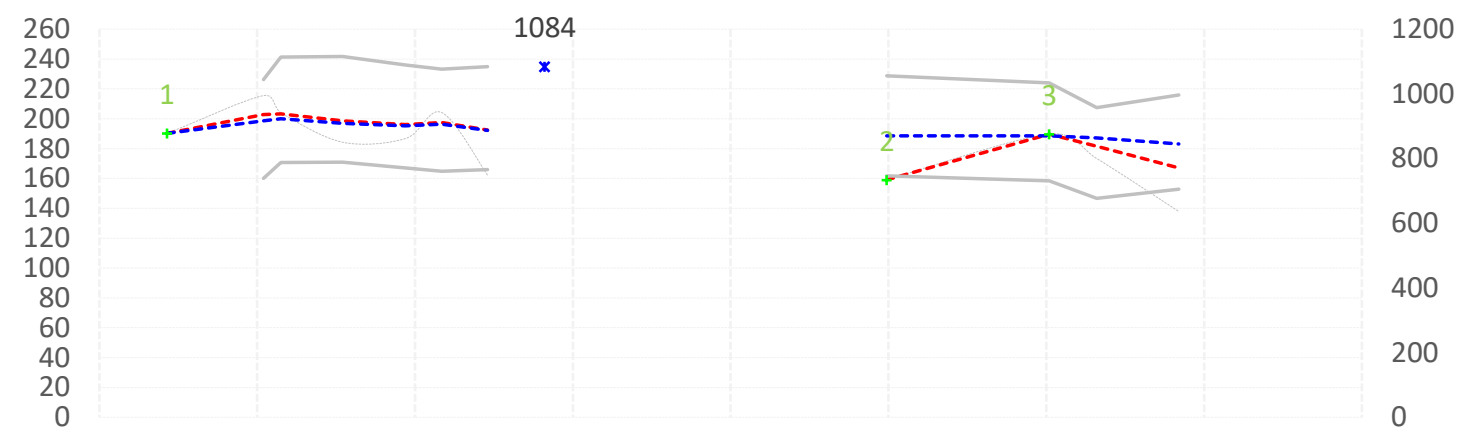

Fonte: Elaboração própria 
Em POLI5, o informante proferiu 15 UBIs e fez somente uma frase entoacional. Antes da primeira pausa, foram realizadas 8 UBIs para demarcar o trecho "não conseguiu dormir... mas", e houve uma breve interrupção de 549 ms. O segundo trecho, "ao amanhecer", é realizado e possuirá a pausa de $519 \mathrm{~ms}$ antes do encerramento do último período "lembrou-se de todos os seus sonhos", como visto no gráfico 5. Nele, repetem-se as orientações do gráfico 4, considerando-se que os asteriscos marcam o início da pausa em 549 ms e 519 ms.

Gráfico 5. Na figura abaixo, tem-se a representação da pausa
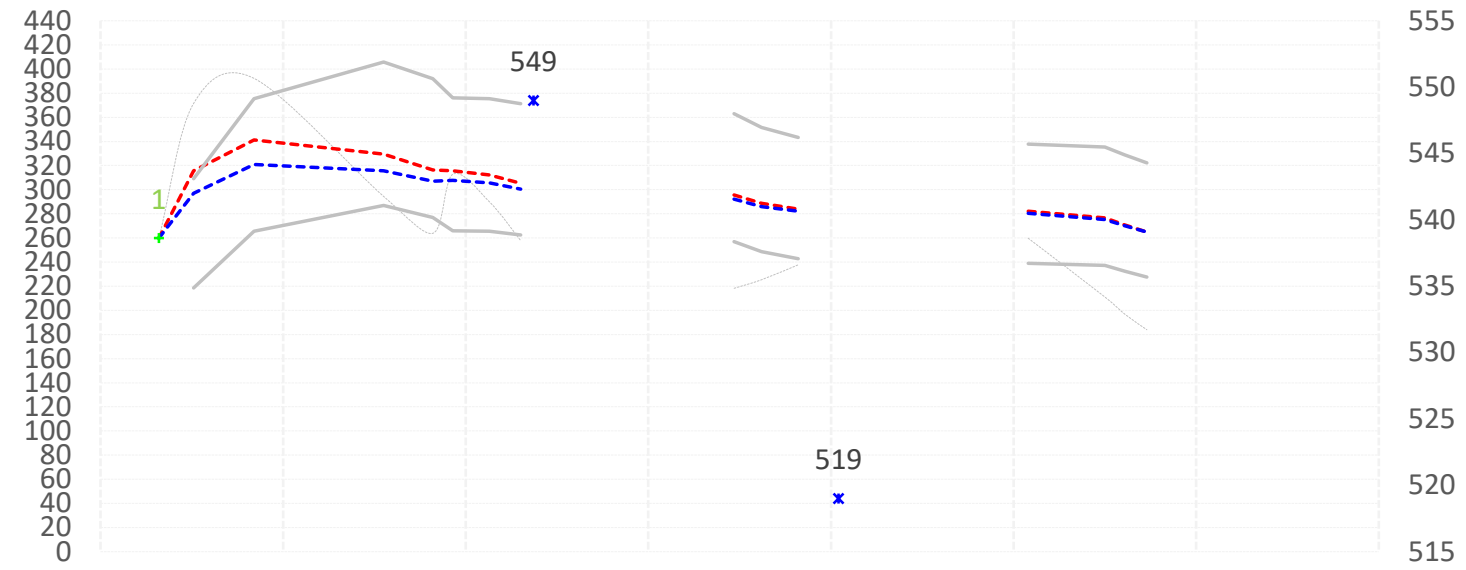

Fonte: Elaboração própria

Dessa forma, percebemos a ausência de uma estabilidade entre os profissionais, ainda que $85 \%$ dos professores analisados produziram pausas perceptuais ao final do $1^{\circ}$ período do conto. Mesmo mediante desse resultado favorável em que houve respeito à pontuação, tivemos 17,5\% de informantes que realizaram uma pausa perceptual após a subordinada adverbial temporal ("ao amanhecer"); $10 \%$ não promoveram pausas reais e apenas $2 \%$ fizeram uma breve interrupção após a conjunção adversativa.

\section{Considerações finais}

Na nova obra Prosódia, de Barbosa (2019, p. 82), é dito que a prosódia e a sintaxe são incongruentes, ratificando Cagliari (2002) ao afirmar que o texto escrito e sua lógica podem não ser seguidos na reinterpretação oral do texto. O fato que esta pesquisa demonstra que ambas as afırmações estão corretas, mesmo quando se tratam de leituras realizadas por professores que, devido ao seu ambiente escolar, teoricamente poderiam ter um efeito de leitura padronizado para ser passado aos alunos. 
Embora tenhamos resultados semelhantes em determinados casos, como a realização de movimentos oblíquos ou a direção entoacional descendente, os quais auxiliam a demarcar a pausa silenciosa, o fato de não termos bem determinada a finalização, se plagal ou autêntica, pode confundir o aluno, tendo em vista que o alvo plagal demonstra uma articulação menos acentuada em relação às finalizações das frases entoacionais. E tal apontamento agrava-se quando percebemos que a produção de UBIs não são determinantes para estabelecer essa boa relação de pronúncia, da execução das unidades sonoras, tendo em vista que não há uma determinação de pausas perceptíveis e reais entre elas, de maneira que a divisão de frases entoacionais seja clara para todos.

Sendo assim, mesmo sabendo que a leitura é realizada de acordo com a intuição do enunciador, levanta-se a questão de como isso é pertinente para o aluno que, em idade escolar, está construindo sua percepção de mundo e estabelecendo princípios para a sua própria compreensão de texto. Sem um regramento ou a aceitação de que uma leitura, independentemente do gênero tratado, é realizada de maneira neutra, como tais atitudes podem auxiliar o desenvolvimento cognitivo de nossos estudantes?

Com esta pesquisa, percebe-se que a ausência de uma estandardização é uma realidade que parte dos professores, e é claro afirmar que isso não se trata de uma crítica, mas de uma observação relevante que pode responder perguntas ligadas ao processo educacional, como o porquê de um aluno não compreender determinados gêneros, ou compreender o conteúdo de um profissional e não do outro de uma mesma disciplina, por exemplo. Logo, são pontos a serem mais pesquisados, de modo a auxiliar nossos processos de como se ler, além de apenas ler uma determinada informação.

\section{REFERÊNCIAS}

BARBOSA, P. Prosódia. São Paulo: Parábola, 2019.

CAGLIARI, L. C. Da importância da prosódia na descrição de fatos gramaticais. In: ILARI, R. Gramática do português falado. v. II: Níveis de análise linguística. Campinas: Editora da UNICAMP, 2002. p. 37-60.

DAHLET, V. A pontuação e as culturas da escrita. Filologia e Linguística Portuguesa, n. 8, p. 287-314, 2006.

FERREIRA-NETTO, W. ExProsódia: Resultados preliminares. São Paulo: Ed. Paulistana, 2016. 
FERREIRA NETTO, W. Decomposição da entoação frasal em componentes estruturadoras e em componentes semântico-funcionais. In: IV CONGRESSO

INTERNACIONAL DE FONÉTICA E FONOLOGIA, 2008, Niterói. Caderno de Resumos. v. 1. Niterói: UFF. 2008. p. 26-27.

FERREIRA NETTO, W. ExProsódia. Revista da Propriedade Industrial - RPI, 2038, p. 167, item 120, 2010. Disponível em: http://revistas.inpi.gov.br/pdf/PATENTES2038.pdf. Acesso em: 20 jul. 2017.

FERREIRA NETTO, W.; CONSONI, F. Estratégias prosódicas da leitura em voz alta e da fala espontânea. Alfa: Revista de Linguística, São José do Rio Preto: UNESP, v. 52, p. 521-534, 2008.

MARTINS, M. V. M.; FERREIRA NETTO, W. Retomada do tom médio após intervalos de sonoridade. Gradus - Revista Brasileira de Fonologia de Laboratório, Curitiba, v. 4, n. 2, p. 11-31, 2020. Disponível em: https://gradusjournal.com/index.php/gradus/article/ view/133 . Acesso em: 7 nov. 2020.

FÓNAGY, I. Des fonctions de l'intonation: Essai de synthèse. Flambeau, Tokio, n. 29, p. 1-20, 2003.

HUCKVALE, M. A. Speech Filing System v.4.7/Windows SFSWin Version 1.7, em 17/02/2008. Disponível em: http://www.phon.ucl.ac.uk/resource/sfs. Acesso em: 20 jul. 2013.

GARCIA, R. R. A entoação do dialeto caipira do Médio Tietê: reconhecimento, características e formação. 2015. Tese (Doutorado em Filologia e Língua Portuguesa) - Faculdade de Filosofia, Letras e Ciências Humanas, Universidade de São Paulo, São Paulo, 2015.

MARCUSCHI, L. A. Análise da conversação. São Paulo: Ática, 2003.

NESPOR, M.; VOGEL, I. Prosodic phonology. Dordrecht: Foris, 1986.

SILVA, N. Sonhos. Miniconto. 08 nov. 2017. Disponível em http://www. minicontos.com. $\mathrm{br} /$ ?apid=6820\&tipo=2\&dt=0\&wd=\&titulo=Sonhos. Acesso em: 20 abr. 2018.

XU, Y.; WANG, Q. E. Component of intonation: what are linguistic, what are mechanical/ physiological? Presented at International Conference on Voice Physiology and Biomechanics, Evanston Illinois, 1997. 